Article

\title{
Neoflavonoids as Inhibitors of HIV-1 Replication by Targeting the Tat and NF- $k$ B Pathways
}

Dionisio A. Olmedo ${ }^{1, *}$, José Luis López-Pérez ${ }^{1}$, Esther del Olmo ${ }^{1}$, Luis M. Bedoya ${ }^{4,5}$, Rocío Sancho $^{2}$, José Alcamí ${ }^{4}$, Eduardo Muñoz ${ }^{2}$, Arturo San Feliciano ${ }^{1}$ and Mahabir P. Gupta ${ }^{3, *}$

1 Pharmaceutical Chemistry Area, Department of Pharmaceutical Sciences, University of Salamanca, Faculty of Pharmacy, CIETUS, IBSAL, Campus Miguel de Unamuno, 37007 Salamanca, Spain; lopez@usal.es (J.L.L.-P.); olmo@usal.es (E.d.O.); artsf@usal.es (A.S.F.)

2 Department of Cellular Biology, Physiology and Immunology, University of Córdoba, Faculty of Medicine Avda de Menendez Pidal s/n, 14004 Córdoba, Spain; Rocio.Sancho@cancer.org.uk (R.S.); fi1muble@uco.es (E.M.)

3 CIFLORPAN, Center for Pharmacognostic Research on Panamanian Flora, College of Pharmacy, University of Panama, P.O. Box 0824-00172 Panama, Panama

4 National Centre of Microbiology, Institute Carlos III, Crt. Majadahonda a Pozuelo, 28220 Majadahonda, Madrid, Spain; lmbedoya@ucm.es (L.M.B.); ppalcami@isciii.es (J.A.)

5 Pharmacology Department, College of Pharmacy, Complutense University. Pz. Ramón Y Cajal s/n, 28040 Madrid, Spain

* Correspondence: dolmedoagudo@hotmail.com (D.A.O.); mahabirpgupta@gmail.com (M.P.G.); Tel.: +507-523-6311 (M.P.G.); Fax: +507-264-0789 (M.P.G.)

Academic Editor: Derek J. McPhee

Received: 12 January 2017; Accepted: 16 February 2017; Published: 19 February 2017

\begin{abstract}
Twenty-eight neoflavonoids have been prepared and evaluated in vitro against HIV-1. Antiviral activity was assessed on MT-2 cells infected with viral clones carrying the luciferase reporter gene. Inhibition of HIV transcription and Tat function were tested on cells stably transfected with the HIV-LTR and Tat protein. Seven 4-phenylchromen-2-one derivatives showed HIV transcriptional inhibitory activity but only the phenylchrome-2-one $\mathbf{1 0}$ inhibited NF- $\mathrm{KB}$ and displayed anti-Tat activity simultaneously. Compounds 10, 14, and 25, inhibited HIV replication in both targets at concentrations $<25 \mu \mathrm{M}$. The assays of these synthetic 4-phenylchromen-2-ones may aid in the investigation of some aspects of the anti-HIV activity of such compounds and could serve as a scaffold for designing better anti-HIV compounds, which may lead to a potential anti-HIV therapeutic drug.
\end{abstract}

Keywords: neoflavonoids; 4-phenyl-chromen-one; AIDS; Tat protein; NF-kB inhibition; anti-HIV activity

\section{Introduction}

UNAIDS report in 2016 indicated that tuberculosis remains the leading cause of death among people living with HIV, accounting for around one in three AIDS-related deaths. In 2014, the percentage of identified HIV-positive tuberculosis patients who started or continued on ART reached 77\% [1]. This relevant fact should promote further studies to take advantage of this therapeutic ambivalence and to evaluate the possibility of using 4-phenylchromene-2-ones for treating patients suffering from both AIDS and tuberculosis.

Human immunodeficiency virus (HIV) is the cause of acquired immunodeficiency syndrome (AIDS) which is one of the leading causes of $2.9 \%$ of mortality in the world [2]. Although modern antiretroviral therapy (ART) using a combination of anti-HIV drugs has been highly effective in suppressing HIV load and decreasing mortality in AIDS patients, the emergence of drug resistances in HIV and the toxicity of the therapies currently in use have made the continued search for novel anti-HIV drugs necessary [3,4]. On the other hand, failures in efforts to develop an effective vaccine 
against HIV-1 infection [5] have emphasized the importance of ART in treating HIV-1-infected patients. Therefore, medicinal chemists are interested in the development of novel anti-HIV agents that might be particularly effective in controlling strains of HIV that are resistant to the current drugs [6].

The HIV viral cycle can be divided into early and late stages. Early stages comprise several steps, from viral attachment on the cell surface to integration in the host genome. Late stages include the processes of HIV mRNA synthesis, protein expression and morphogenesis. Once integrated, HIV can remain in a latent state in resting lymphocytes or undergo active replication. Transition from latency to HIV expression occurs mainly when cells are activated and requires the concerted action of cellular transcription factors and regulatory HIV proteins [7,8]. Among the transcription factors involved in LTR transactivation, the HIV proximal enhancer contains three binding sites for SP1 transcription factor and two binding sites for NF- $\mathrm{kB}$. The NF- $\mathrm{kB} /$ Rel family of transcription factors represents a major inducible regulatory element involved in HIV transcription [9]. Located downstream of the basal promoter TAR sequence is the RNA target for the viral protein Tat, which acts in concert with other cellular factors [10], to generate full-length RNA transcripts [11]. Furthermore, NF-kB and Tat cooperate in driving HIV replication from the state of latency. Therefore, inhibition of the activity of these critical proteins should result in an effective blocking of viral replication [12-14].

The neoflavonoids with anti-HIV activity possessing 4-phenylcoumarin skeleton have been obtained mainly from Calophyllaceae family that includes the genera: Calophyllum [15-21]; Mammea [21-26]; Mesua [27-33]; Kielmeyera [34-38]; and Marila [39], from which several 4-phenyl chromen-2-one derivatives have been isolated.

The discovery, structural modification and structure-activity relationships studies of natural neoflavonoids with anti-HIV activity:(+)-Inophyllum B [40], (+)-Inophyllum C [19], and Inophyllum $\mathrm{P}$ [40], and a number of their synthetic derivatives have been successfully obtained in this work. These 4-phenylcoumarins have been proposed as suppressors of LTR-dependent transcription, but the mechanism of action has not been fully characterized [41]. In addition, isomesuol and mesuol inhibit TNF- $\alpha$-induced HIV-1-LTR transcriptional activity by targeting the nuclear factor- $\mathrm{kB}$ (NF- $\mathrm{kB}$ ) pathway. Mesuol inhibited the phosphorylation and the transcriptional activity of the NF- $\mathrm{kB}$ p65 subunit in TNF $\alpha$-stimulated cells [42]. Isodispar B and Disparinol A are HIV transcription inhibitors, which inhibit both, NF- $\mathrm{KB}$ and Tat targets, affecting the HIV replication by synergistic effect [43]. Synthetic 4-phenylchromen-2-ones have been also reported to show antimicrobial [30,44,45], anti-mycobacterial [46] and anti-inflammatory activities [47].

In a previous paper we reported the anti-HIV activity of natural 4-phenylcoumarins isolated from Marila pluricostata. They were structurally related to Inophyllum coumarins series, but with one prenyl and other cyclized group across the hydroxyl group at position C-7 [43]. Furthermore, these compounds showed moderate anti-mycobacterial activity. This relevant fact induced us to prepare new similar, but simpler, derivatives with the idea in mind to obtain compounds with activity against both HIV and tuberculosis, and also to increase the structural diversity. With that, a better structure-activity relationship could be established. In this paper we reported the preparation and the anti-HIV activity of several neoflavone derivatives that showed anti-mycobacterial activity [48].

\section{Results and Discussion}

\subsection{Chemistry}

The 4-phenylchromen-2-ones or neoflavones 1-7 have been obtained by the Peckman condensation between ethyl benzoylacetate and different phenol derivatives that is, resorcinol for $\mathbf{1}$, phloroglucinol for 2, hydroxyhydroquinone for 3, 3,4-methylenedioxyphenol for 4, 3-methoxycatechol for 5, 2,3-dimethoxyphenol for 6 and $\beta$-naphthol for 7 in presence of concentred $\mathrm{H}_{2} \mathrm{SO}_{4}$ as condensing agent (Scheme 1). Some differences in the yield of the different compounds can be appreciated depending on the phenol derivative used (see the Experimental Section). 
<smiles>[R]c1cc(O)c([R])c([R])c1[R]</smiles>
(i) Pechmann condensation conditions $\mathrm{H}_{2} \mathrm{SO}_{4}$, r.t. $96 \mathrm{~h}$

1: $\mathrm{R}^{2}=\mathrm{OH}, \mathrm{R}^{1}=\mathrm{R}^{3}=\mathrm{R}^{4}=\mathrm{H}$

2: $R^{2}=R^{4}=O H, R^{1}=R^{3}=H$

3: $\mathrm{R}^{2}=\mathrm{R}^{3}=\mathrm{OH}, \mathrm{R}^{1}=\mathrm{R}^{4}=\mathrm{H}$

4: $\mathrm{R}^{2}=\mathrm{OCH}_{2} \mathrm{O}=\mathrm{R}^{3}, \mathrm{R}^{1}=\mathrm{R}^{4}=\mathrm{H}$

5: $\mathrm{R}^{1}=\mathrm{OH}, \mathrm{R}^{2}=\mathrm{OMe}, \mathrm{R}^{3}=\mathrm{R}^{4}=\mathrm{H}$

6: $R^{1}=R^{2}=O M e, R^{2}=R^{4}=H$

7: $\mathrm{R}^{3}=-\mathrm{CH}=\mathrm{CH}-\mathrm{CH}=\mathrm{CH}-=\mathrm{R}^{2}, \mathrm{R}^{1}=\mathrm{R}^{4}=\mathrm{H}$

Scheme 1. Preparation of 4-phenylcoumarins 1-7.

Phloroglucinol, as the starting material (Scheme 1), was treated with ethyl benzoylacetate by the Pechmann-Duisberg reaction giving 5,7-dihydroxy-4-phenylcoumarin (2). Friedel-Craft acylation or benzoylation of compound 2 , by refluxing the phenol derivative with the corresponding acylchloride in a carbon disulfide/nitrobenzene mixture, and in the presence of aluminum trichloride, followed by Fries rearrangement provided mixtures of the 6-, 8-monoacylated and benzoylated neoflavones and 6,8-diacylated or dibenzoylated neoflavones [49-52]. Workup of the crude reaction products led to the isolation of neoflavones 8-21 whose spectroscopic properties were consistent with the structures shown in the Scheme 2. On the basis of detailed analysis of the H-H COSY (Correlation Spectroscopy), H-C HMQC (Heteronuclear Single Quantum Correlation), and H-C HMBC (Heteronuclear Multiple-Bond Correlation) 2D-NMR spectra, all of the compounds described were correctly characterized and their ${ }^{13} \mathrm{C}-\mathrm{NMR}$ data will be introduced in NAPROC-13 RMN spectroscopic database [53], for posterior online identification of natural products and their analogs and derivatives.<smiles>O=c1cc(-c2ccccc2)c2c(O)cc(O)cc2o1</smiles>

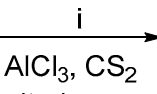

for comp. 8: (i) allyl bromide

${ }^{b}$ for comps 9, 14, 19: (i) isovaleroyl chloride

${ }^{c}$ for comps 10, 15, 20: (i) heptanoyl chloride

$\mathrm{d}_{\text {for comps 11, 16: (i) benzoyl chloride }}$

e for comps 12, 17: (i) acetyl chloride

f for comps 13, 18: (i) propionyl chloride

$\mathrm{g}$ for comp. 21 (i) benzyl bromide<smiles>[R]c1c(O)c(O)c2c(-c3ccccc3)cc(=O)oc2c1[R]</smiles>

8: $R^{1}=H, R^{2}=A l l y l$

9: $R^{1}=H, R^{2}=$ isovaleroyl

10: $R^{1}=H, R^{2}=$ heptanoyl

11: $R^{1}=H, R^{2}=$ benzoyl

12: $R^{1}=$ acetyl, $R^{2}=H$

13: $R^{1}=$ propionyl, $R^{2}=H$

14: $R^{1}=$ isovaleroyl, $R^{2}=H$

15: $R^{1}=$ heptanoyl, $R^{2}=H$

16: $R^{1}=$ benzoyl, $R^{2}=H$

17: $R^{1}=R^{2}=$ acetyl

18: $R^{1}=R^{2}=$ propionyl

19: $R^{1}=R^{2}=$ isovaleroyl

20: $R^{1}=R^{2}=$ heptanoyl

21: $R^{1}=R^{2}=H, 5,7=$ benzylether

Scheme 2. Preparation of neoflavanones 8-21. 
Neoflavones 22-28 were obtained by the condensation of substituted cinnamic acids with the corresponding phenols, that is, phenol for 22, resorcinol for 23 and 24, 3,5-dichlorophenol for 25, 3,4-methylenedioxyphenol for $\mathbf{2 6}$ and 27, and 3-methoxybenzene-1,2-diol for $\mathbf{2 8}$. The reaction occurred in the presence of milder Friedel-Crafts catalyst $\mathrm{BF}_{3}-\mathrm{Et}_{2} \mathrm{O}$ and $\mathrm{POCl}_{3}$ in $54 \%-75 \%$ yields (Scheme 3 ). Previous attempts towards condensation of substituted cinnamic acids with corresponding phenols for the preparation of 4-phenylchromen-2-ones 22-28 in the presence of concentrated $\mathrm{HCl}$ and $\mathrm{HCl}$ gas were unsuccessful. Additionally, some of these compounds were synthesized in low yields by microwave irradiation.

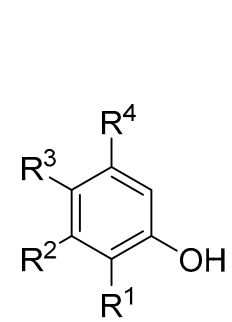

(i) $\mathrm{BF}_{3} \mathrm{EtO}_{2} / \mathrm{POCl}_{3}$, r.t., $\mathrm{N}_{2}, 4-16 \mathrm{~h}$

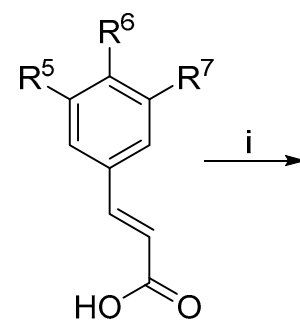<smiles>[R]c1cc(C2CC(=O)Oc3c([R])c([R])c([R])c([R])c32)cc([R])c1[R6]</smiles>

22: $R^{6}=O M e, R^{1}=R^{3}=R^{4}=R^{5}=R^{7}=H$

23: $\mathrm{R}^{2}=\mathrm{OH}, \mathrm{R}^{5}=\mathrm{R}^{6}=\mathrm{OMe}, \mathrm{R}^{1}=\mathrm{R}^{3}=\mathrm{R}^{4}=\mathrm{R}^{7}=\mathrm{H}$

24: $R^{2}=O M e, R^{6}=O M e, R^{1}=R^{3}=R^{4}=R^{5}=R^{7}=H$

25: $R^{2}=R^{4}=C l, R^{1}=R^{3}=R^{5}=R^{6}=R^{7}=H$

26: $\mathrm{R}^{2}=\mathrm{R}^{3}=\mathrm{OCH}_{2} \mathrm{O}, \mathrm{R}^{5}=\mathrm{R}^{7}=\mathrm{OMe}, \mathrm{R}^{6}=\mathrm{OH}, \mathrm{R}^{1}=\mathrm{R}^{4}=\mathrm{H}$

27: $\mathrm{R}^{2}=\mathrm{R}^{3}=\mathrm{OCH}_{2} \mathrm{O}, \mathrm{R}^{5}=\mathrm{R}^{6}=\mathrm{R}^{7}=\mathrm{OMe}, \mathrm{R}^{1}=\mathrm{R}^{4}=\mathrm{H}$

28: $R^{1}=O H, R^{2}=O M e, R^{5}=R^{6}=R^{7}=O M e, R^{3}=R^{4}=H$

Scheme 3. Preparation of neoflavones 22-28.

Some compounds prepared in this study have been described already in the literature (see the Experimental Section) and their structures were verified from an iterative search by ${ }^{13} \mathrm{C}-\mathrm{NMR}$ chemical shifts carried out within our NAPROC-13 RMN spectroscopic database [53], and later identified unambiguously. The rest of the prepared 4-phenylcoumarins were established on the basis of ${ }^{1} \mathrm{H}-$ and ${ }^{13} \mathrm{C}-\mathrm{NMR}$ spectra. A combination of COSY, HMQC, and NOE experiments was utilized when necessary for a correct assignment of ${ }^{1} \mathrm{H}$ and ${ }^{13} \mathrm{C}$ chemical shifts.

The synthesized neoflavonoids 1-8 were evaluated in vitro against HIV-1 with the results shown in Table 1.

\subsection{Evaluation of Antiviral Activity}

The neoflavonoids synthesized (1-28) belong to three groups: simple 4-phenylchromen-2-ones, acyl-4-phenylchromen-2-ones and 3,4-dihydro-4-phenylchromen-2-ones, which have been evaluated in the anti HIV bioassay. The analysis of the results of inhibitory activity of NF- $\mathrm{kB}$ indicates that 4-phenylchromenones $\mathbf{9}, \mathbf{1 0}, \mathbf{1 3}, \mathbf{1 4}$, and 15 show a fair inhibitory activity at $50 \mu \mathrm{M}$. Regarding the specific HeLa-Tat-Luc assay results, compounds 9, 13, and 15 were nonspecific, whereas compounds 10 and 14 showed specificity. Furthermore compound $\mathbf{1 4}$ is only slightly toxic at $50 \mu \mathrm{M}$, but not toxic at $25 \mu \mathrm{M}$, and their activity as NF- $\mathrm{KB}$ and tat inhibitors is still strong $(83.06 \%$ for NF- $\mathrm{KB}$ and $41.87 \%$ for Tat). Compound $\mathbf{1 4}$ turned out to be identical to the natural neoflavonoid Isodispar B previously isolated from Marila pluricostata [43]. Compound $10 \mathrm{NF- \kappa B}$ activity is also strong (70.53 at $25 \mu \mathrm{M})$ and it is nontoxic at $10 \mu \mathrm{M}$. Interestingly, the dichlorinated 3,4-dihydroflavonoid 25 showed specific anti-Tat activity, whereas all other 3,4-dihydroanalogs resulted inactive in this assay. It must be noted that simple structural differences within this series of 4-phenylchromen-2-ones and acyl 4-phenylchromen-2-ones, determine substantial changes in activity and selectivity. As an example, we could compare the specific NF- $\mathrm{KB}$ inhibitor 8-isovaleroyl-4-phenylchromen-2-one $\mathbf{1 4}$ and the specific 
Tat inhibitor 3,4-dihydro-5,7-dichloro-4-phenyl-chroman-2-one 25, also a 4-phenylchromen related. The drastic difference in bioactivity for these compounds should be due either to the presence of an isovaleroyl or heptanoyl group in C-6 or C-8, which potentiates the activity in both targets. However, regarding the comparison of compounds 7 and 14, it is worth noting that the presence of a benzene ring fused to the chromenone moiety, increases the anti-Tat activity, but the introduction 8-isovaleroyl or 6,8-diacetyl groups enhances the NF-KB inhibitory activity. Compound 10, when compared to Disparinol A, showed higher anti-HIV potency than this natural neoflavonoid. The acyl derivatives of 4-phenylchromen-2-ones are the most potent dual-target inhibitors.

The assays of these 4-phenyl-chromen-2-one derivatives may aid in the investigation of some aspects of the anti-HIV activity of this kind of compound that inhibited the transcription and could serve as a scaffold for designing better anti-HIV compounds, which may lead to a potential HIV therapeutic drug.

Table 1. Anti-HIV Activity of neoflavonoids.

\begin{tabular}{|c|c|c|c|c|c|c|}
\hline \multirow[t]{2}{*}{ Compound } & \multicolumn{2}{|c|}{ NF-KB (5.1 LTR) } & \multicolumn{2}{|c|}{ Hela-Tat-luc } & \multirow{2}{*}{$\begin{array}{c}\begin{array}{c}\text { Specificity } \\
\text { (HeLa-Tet-On-Luc) }\end{array} \\
50 \mu \mathrm{M}\end{array}$} & \multirow{2}{*}{$\begin{array}{r}\begin{array}{r}\text { Toxicity } \\
\text { MT2 (\%) }\end{array} \\
50 \mu \mathrm{M}\end{array}$} \\
\hline & $25 \mu \mathrm{M}$ & $50 \mu \mathrm{M}$ & $25 \mu \mathrm{M}$ & $50 \mu \mathrm{M}$ & & \\
\hline 1 & NT & -11.28 & NT & 27.88 & $\mathrm{NT}$ & 18.40 \\
\hline 2 & NT & -4.10 & NT & -7.43 & NT & 8.78 \\
\hline 3 & NT & 34.27 & NT & 6.59 & NT & 2.22 \\
\hline 4 & 7.30 & 21.66 & 5.58 & 34.64 & $\mathrm{~S}$ & 3.55 \\
\hline 5 & 22.98 & 23.83 & -2.63 & 44.60 & $\mathrm{~S}$ & 11.30 \\
\hline 6 & NT & 19.12 & NT & 16.25 & NT & 2.88 \\
\hline 7 & NT & 51.71 & NT & 94.69 & $\mathrm{U}$ & 4.00 \\
\hline 8 & NT & 9.25 & NT & 21.74 & NT & 8.33 \\
\hline 9 & NT & 68.74 & NT & 80.84 & $\mathrm{U}$ & NT \\
\hline 10 & 70.53 & 68.19 & NT & 83.32 & $S$ & $<10$ \\
\hline 11 & NT & 37.81 & NT & 26.63 & S & NT \\
\hline 12 & NT & 20.40 & NT & 5.81 & $\mathrm{~S}$ & NT \\
\hline 13 & NT & 67.29 & NT & 66.72 & $\mathrm{U}$ & NT \\
\hline 14 & 83.06 & 86.60 & 41.87 & 69.32 & $S$ & 17.02 \\
\hline 15 & NT & 79.41 & NT & 80.37 & $\mathrm{U}$ & NT \\
\hline 16 & NT & -17.05 & NT & 20.87 & $S$ & NT \\
\hline 17 & NT & 83.70 & NT & 44.93 & $\mathrm{U}$ & NT \\
\hline 18 & NT & 35.05 & NT & 30.20 & $S$ & NT \\
\hline 19 & 59.86 & 66.04 & NT & 12.99 & S & NT \\
\hline 20 & NT & 10.70 & NT & 22.30 & $S$ & NT \\
\hline 22 & NT & 15.20 & NT & 6.06 & NT & 1.61 \\
\hline 23 & NT & 11.94 & NT & -34.54 & NT & 2.55 \\
\hline 24 & 36.95 & 43.21 & NT & -18.03 & NT & 2.00 \\
\hline 25 & 35.20 & 53.99 & 57.46 & 72.27 & $\mathrm{~S}$ & 3.50 \\
\hline 26 & NT & 13.37 & NT & -28.08 & NT & 2.59 \\
\hline 27 & NT & 20.48 & NT & 15.08 & NT & 4.73 \\
\hline 28 & NT & 5.67 & NT & -65.28 & NT & 6.13 \\
\hline Mesuol & 71.00 & 77.90 & NT & 71.30 & $\mathrm{~S}$ & $>4 \mu \mathrm{M}$ \\
\hline
\end{tabular}

$\mathrm{S}=$ Specific activity $; \mathrm{U}=$ Unspecific mode of action; NT = Not tested.

\section{Experimental Section}

\subsection{General Information}

All of the reagents for synthesis were commercially available and either used without further purification or purified by standard methods prior to use. Melting points were determined on a Büchi 510-K melting point apparatus (Büchi Labortechnik AG, Flawil, Switzerland) and are uncorrected. IR spectra were recorded ( $\mathrm{KBr} 1 \%)$ in a Nicolet Impact 410 spectrophotometer. ${ }^{1} \mathrm{H}-,{ }^{13} \mathrm{C}-\mathrm{NMR}, \mathrm{COSY}$, 
HMQC, and HMBC were recorded on Brüker AC 200 (200 MHz) and Brüker DRX 400 (400 MHz) instruments. Chemical shifts $(\delta)$ are expressed in parts per million $(\mathrm{ppm})$ relative to the residual solvent peak, and coupling constants are reported in $\mathrm{Hertz}(\mathrm{Hz})$. All signals assigned to hydroxyl groups were exchangeable with $\mathrm{D}_{2} \mathrm{O}$. Reaction progress was monitored using analytical thin-layer chromatography (TLC) on precoated Merck silica gel Kiesegel $60 \mathrm{~F}_{254}$ plates, and the spots were detected under UV light $(254 \mathrm{~nm})$. The flash chromatography was conducted using silica gel $230-400$ mesh. For EIMS and HRFABMS analysis, a VG-TS250 mass spectrometer $(70 \mathrm{eV})$ was used. Elementary analyses were obtained with a LECO CHNS-932 and were within $\pm 0.4 \%$ of the theoretical values.

\subsection{General Procedures I for the Synthesis of Compounds 1-7}

To a mixture of appropriate phenol $(2 \mathrm{mmol})$ and ethyl benzoyl acetate $(2 \mathrm{mmol})$, concentrated $\mathrm{H}_{2} \mathrm{SO}_{4},(1 \mathrm{~mL})$ was added and stirred at room temperature for four days; after which the mixture was poured over crushed ice and extracted with $\mathrm{AcOEt},(50 \mathrm{~mL} \times 5)$. Evaporation gave a brown solid which, after chromatography (silica gel, hexane/AcOEt 10:1 $\rightarrow 1: 1$ ), afforded the corresponding 4-phenylcoumarin (1-7) as a white solid (yield, $25 \%-30 \%$ ).

7-Hydroxy-4-phenyl-2H-chromen-2-one (1). Yield 85\%; A white solid; m.p. 232-234 ${ }^{\circ} \mathrm{C}(\mathrm{MeOH})$. The spectral data $\left({ }^{1} \mathrm{H}-\mathrm{NMR}\right)$ were quite comparable with the data reported in [54].

5,7-Dihydroxy-4-phenyl-2H-chromen-2-one (2). Yield 70\%; A white solid; m.p. 227-229 ${ }^{\circ} \mathrm{C}(\mathrm{MeOH})$. The spectral data $\left({ }^{1} \mathrm{H}-\mathrm{NMR}\right)$ were quite comparable with the data reported in [52].

6,7-Dihydroxy-4-phenyl-2H-chromen-2-one (3). Yield 68\%; A white solid; m.p. $230-232{ }^{\circ} \mathrm{C}\left(\mathrm{CHCl}_{3} / \mathrm{MeOH}\right)$; IR (KBr): $v=3437,3414,1686,1617,1562 \mathrm{~cm}^{-1} ;{ }^{1} \mathrm{H}-\mathrm{NMR}(\mathrm{MeOD}) \delta 7.52(\mathrm{~m}, 2 \mathrm{H}), 7.52(\mathrm{~m}, 3 \mathrm{H}), 6.86(\mathrm{~s}$, 1H), $6.83(\mathrm{~s}, 1 \mathrm{H}), 6.13(\mathrm{~s}, 1 \mathrm{H}) ;{ }^{13} \mathrm{C}-\mathrm{NMR}(\mathrm{MeOD}) \delta 104.0,111.3,111.9,112.3,129.4,129.4,129.9,129.9$, 130.6, 137.2, 144.4, 150.5, 152.0, 158.4, 164.1. MS (EI) $m / z: 254\left(\mathrm{M}^{+} \mathrm{C}_{15} \mathrm{H}_{10} \mathrm{O}_{4}, 8\right), 252$ (52), 224 (100), $152(80), 139$ (13).

8-Phenyl-6H-[1,3]dioxolo[4,5-g]chromen-6-one (4). Prepared from benzo[d][1,3]dioxol-5-ol (2 mol) as described in the general procedure I. Yield $65 \%$; A white solid; m.p. $190-192{ }^{\circ} \mathrm{C}\left(\mathrm{CDCl}_{3} / \mathrm{MeOH}\right)$. IR $(\mathrm{KBr}): v=1712,1627,1563,1503 \mathrm{~cm}^{-1} ;{ }^{1} \mathrm{H}-\mathrm{NMR}(\mathrm{CDCl} 3) \delta 7.50(\mathrm{~m}, 3 \mathrm{H}), 7.41(\mathrm{~m}, 2 \mathrm{H}), 6.86(\mathrm{~s}, 1 \mathrm{H}), 6.82$ $(\mathrm{s}, 1 \mathrm{H}), 6.22(\mathrm{~s}, 1 \mathrm{H}), 6.04(\mathrm{~s}, 2 \mathrm{H}) ;{ }^{13} \mathrm{C}-\mathrm{NMR}\left(\mathrm{CDCl}_{3}\right) \delta 98.5,102.3,104.3,112.1,112.8,128.2,128.2,128.8$, 128.8, 129.6, 135.6, 144.8, 151.1, 151.2, 155.8, 161.1. MS (EI) $m / z: 266\left(\mathrm{M}^{+} \mathrm{C}_{16} \mathrm{H}_{10} \mathrm{O}_{4}, 66\right), 265$ (88), 238 (100), 152 (22).

8-Hydroxy-7-methoxy-4-phenyl-2H-chromen-2-one (5). Prepared as described in general procedure I from 3-methoxybenzene-1,2-diol (2 mmol), yield $65 \%$; A white solid; m.p. $220-222{ }^{\circ} \mathrm{C}\left(\mathrm{CDCl}_{3} / \mathrm{MeOH}\right)$; IR (KBr): $v=3342,2937,2838,1697,1562 \mathrm{~cm}^{-1} ;{ }^{1} \mathrm{H}-\mathrm{NMR}(\mathrm{MeOD}) \delta 7.47(\mathrm{~m}, 2 \mathrm{H}), 7.47(\mathrm{~m}, 3 \mathrm{H}), 6.95$ $(\mathrm{d}, J=9.1 \mathrm{~Hz}, 1 \mathrm{H}), 6.87(\mathrm{~d}, J=9.1 \mathrm{~Hz}, 1 \mathrm{H}), 6.15(\mathrm{~s}, 1 \mathrm{H}), 3.94(\mathrm{~s}, 3 \mathrm{H}) ;{ }^{13} \mathrm{C}-\mathrm{NMR}(\mathrm{MeOD}) \delta 56.7,108.7$, 112.1, 114.3, 118.4, 129.2, 129.2, 129.5, 129.5, 130.4, 136.5, 143.8, 151.7, 158.2, 162.7. MS (EI) $\mathrm{m} / \mathrm{z}: 268$ $\left(\mathrm{M}^{+} \mathrm{C}_{16} \mathrm{H}_{12} \mathrm{O}_{4}, 60\right), 265$ (88), 225 (100), 152 (19), 141 (65).

7,8-Dimethoxy-4-phenyl-2H-chromen-2-one (6). This was prepared from 2,3-dimethoxyphenol (2 mol) as described in the general procedure I, yield $70 \%$; A white solid; m.p. $175-177^{\circ} \mathrm{C}\left(\mathrm{CDCl}_{3}\right) ; \mathrm{IR}(\mathrm{KBr})$ : $v=2968,2933,2844,1718,1602,1557 \mathrm{~cm}^{-1} ;{ }^{1} \mathrm{H}-\mathrm{NMR}\left(\mathrm{CDCl}_{3}\right) \delta 7.51(\mathrm{~m}, 3 \mathrm{H}), 7.43(\mathrm{~m}, 2 \mathrm{H}), 7.18(\mathrm{~d}$, $J=9.2 \mathrm{~Hz}, 1 \mathrm{H}), 6.83(\mathrm{~d}, J=9.2 \mathrm{~Hz}, 1 \mathrm{H}), 6.22(\mathrm{~s}, 1 \mathrm{H}), 4.02(\mathrm{~s}, 3 \mathrm{H}), 3.95(\mathrm{~s}, 3 \mathrm{H}) ;{ }^{13} \mathrm{C}-\mathrm{NMR}\left(\mathrm{CDCl}_{3}\right) \delta 56.4$, 61.5, 108.1, 112.3, 113.8, 122.2, 128.4, 128.4, 128.8, 128.8, 129.6, 135.6, 136.5, 148.4, 155.5, 155.9, 160.6. MS (EI) $m / z: 282\left(\mathrm{M}^{+} \mathrm{C}_{17} \mathrm{H}_{14} \mathrm{O}_{4}, 100\right), 267$ (8), 254 (19), 239 (42), 152 (24), 139 (53).

4-Phenyl-2H-benzo[g]chromen-2-one (7). Prepared as described in general procedure II from naphthalen-2-ol (2 mmol), yield 60\%; A white solid; m.p. 211-213 $\left(\mathrm{CDCl}_{3}\right)$; IR (KBr): $v=3054,1722,1633,1593$, $1553 \mathrm{~cm}^{-1} ;{ }^{1} \mathrm{H}-\mathrm{NMR}\left(\mathrm{CDCl}_{3}\right) \delta 8.57(\mathrm{~m}, 1 \mathrm{H}), 7.83(\mathrm{~m}, 1 \mathrm{H}), 7.52-7,62(\mathrm{~m}, 9 \mathrm{H}), 6.44(\mathrm{~s}, 1 \mathrm{H}) ;{ }^{13} \mathrm{C}-\mathrm{NMR}$ $\left(\mathrm{CDCl}_{3}\right) \delta 114.1,114.5,122.3,122.7,123.3,123.9,127.1,127.6,128.5,128.5,128.9,128.9,128.9,129.6,134.8$, 
135.6, 151.4, 156.5, 160.8. MS (EI) m/z: $272\left(\mathrm{M}^{+} \mathrm{C}_{19} \mathrm{H}_{12} \mathrm{O}_{2}, 52\right), 245$ (18), 244 (100), 215 (64), 189 (10), 139 (7).

\subsection{General Procedures II: Synthesis of Compounds 8-22}

Anhydrous aluminum trichloride $(0.4 \mathrm{mmol})$ was added to a stirred suspension of compound $2(0.1 \mathrm{mmol})$ in carbon disulfide $(6 \mathrm{~mL})$. Nitrobenzene $(2 \mathrm{~mL})$ was then added over $40 \mathrm{~min}$, forming a homogeneous solution with evolution of $\mathrm{HCl}$. The solution was heated under reflux for $30 \mathrm{~min}$, appropriate acyl chloride $(0.1 \mathrm{mmol})$ in nitrobenzene $(1 \mathrm{~mL})$ was added over $40 \mathrm{~min}$ before allowing it to cool with stirring. The mixture was poured onto ice/water and aqueous $\mathrm{HCl}$ and was extracted with ethyl acetate $(25 \mathrm{~mL}$, twice). Workup of the crude product by chromatography on silica gel led to the isolation of the different acyl derivatives products.

Following the general procedure II using allyl bromide and benzyl bromide the crude reaction product was chromatographed and eluted with hexane/EtOAc, to yield $\mathbf{8}$ and $\mathbf{2 1 .}$

6-Allyl-5,7-dihydroxy-4-phenyl-2H-chromen-2-one (8). Yield 41\%; A white solid; m.p. $196-198{ }^{\circ} \mathrm{C}$ $\left(\mathrm{CHCl}_{3} / \mathrm{MeOH}\right) ; \mathrm{IR}(\mathrm{KBr}): v=3217,1686,1626,1591 \mathrm{~cm}^{-1} ;{ }^{1} \mathrm{H}-\mathrm{NMR}\left(\mathrm{CDCl}_{3}\right) \delta 7.24(\mathrm{~m}, 2 \mathrm{H}), 7.22(\mathrm{~m}$, $3 \mathrm{H}), 6.55(\mathrm{~s}, 1 \mathrm{H}), 6.36(\mathrm{~s}, 1 \mathrm{H}), 5.70(\mathrm{~m}, 1 \mathrm{H}), 4.82(\mathrm{t}, J=1.8 \mathrm{~Hz}, 1 \mathrm{H}) 4.76(\mathrm{dd}, J=1.2 \mathrm{~Hz}, 1 \mathrm{H}), 3.16(\mathrm{~d}$, $J=6.2 \mathrm{~Hz}, 2 \mathrm{H}) ;{ }^{13} \mathrm{C}-\mathrm{NMR}\left(\mathrm{CDCl}_{3}\right) \delta 26.7,95.8,110.8,110.9,114.5,114.6,127.2,128.9,129.4,135.9,137.3$, 154.3, 154.4, 155.3, 160.1, 161.8. (EI) $m / z: 294\left(\mathrm{M}^{+} \mathrm{C}_{18} \mathrm{H}_{14} \mathrm{O}_{4}, 88\right), 281$ (100), 268 (24), 253(46), 139 (15).

5,7-Dibenzyloxy-4-phenyl-2H-chromen-2-one (21). Yield 45\%; A white solid; m.p. $175-17{ }^{\circ} \mathrm{C}\left(\mathrm{CH}_{2} \mathrm{Cl}_{2}\right)$. IR (KBr): $v=3089,3059,3031,2927,2865,1720,1611,1597,1432,1337,1159,1111,1064,726 \mathrm{~cm}^{-1}$. ${ }^{1} \mathrm{H}-\mathrm{NMR}\left(\mathrm{CDCl}_{3}\right) \delta 7.38(\mathrm{~m}, 3 \mathrm{H}), 7.20(\mathrm{~m}, 5 \mathrm{H}), 7.18(\mathrm{~m}, 10 \mathrm{H}), 5.99(\mathrm{~s}, 1 \mathrm{H}), 6.61(\mathrm{~d}, J=2.4 \mathrm{~Hz}, 1 \mathrm{H})$, $6.41(\mathrm{~d}, J=2.4 \mathrm{~Hz}, 1 \mathrm{H}), 5.10(\mathrm{~s}, 1 \mathrm{H}), 4.72(\mathrm{~s}, 1 \mathrm{H}) .{ }^{13} \mathrm{C}-\mathrm{NMR}\left(\mathrm{CDCl}_{3}\right) \delta 70.5,70.8,94.37,94.87,103.8$, 113.10, 127.03, 127.11, 127.51, 127.62, 127.73, 127.99, 128.25, 128.40, 128.80, 135.08, 135.78, 139.71, 156.74, 157.21, 157.35, 160.74, 162.32. (EI) $m / z: 434\left(\mathrm{M}^{+} \mathrm{C}_{29} \mathrm{H}_{22} \mathrm{O}_{4}, 17\right), 343$ (12), 181 (14), 139 (6), 114 (6), 92 (52), 91 (100).

Following the general procedure II using acetyl chloride, the crude reaction product was chromatographed and eluted with hexane/EtOAc, to yield 12 and 17.

8-Acetyl-5,7-dihydroxy-4-phenyl-2H-chromen-2-one (12). Yield 25\%; A white solid; m.p. 206-208 ${ }^{\circ} \mathrm{C}$ (Hex:AcOEt); IR (KBr): $v=3224,3083,1689,1627,1592 \mathrm{~cm}^{-1} ;{ }^{1} \mathrm{H}-\mathrm{NMR}\left(\mathrm{CDCl}_{3}\right) \delta 14.01(\mathrm{~s}, 1 \mathrm{H}), 7.57$ $(\mathrm{m}, 3 \mathrm{H}), 7.42(\mathrm{~m}, 2 \mathrm{H}), 6.25(\mathrm{~s}, 1 \mathrm{H}), 6.02(\mathrm{~s}, 1 \mathrm{H}), 5.85(\mathrm{~s}, 1 \mathrm{H}), 2.93(\mathrm{~s}, 3 \mathrm{H}) ;{ }^{13} \mathrm{C}-\mathrm{NMR}\left(\mathrm{CDCl}_{3}\right) \delta 32.9$, 99.3, 101.8, 103.7, 110.9, 126.8, 127.2, 127.9, 139.0, 157.9, 158.0, 159.9, 162.0, 167.8, 202.7. (EI) $\mathrm{m} / \mathrm{z}, 272$ $\left(\mathrm{M}^{+} \mathrm{C}_{19} \mathrm{H}_{12} \mathrm{O}_{2}, 52\right), 245$ (18), 244 (100), 215(64), 189 (10). (EI) $m / z: 296\left(\mathrm{M}^{+} \mathrm{C}_{17} \mathrm{H}_{12} \mathrm{O}_{5}, 18\right), 295$ (100), 277 (22), 221(16), 165 (20), 139 (43).

6,8-Diacetyl-5,7-dihydroxy-4-phenyl-2H-chromen-2-one or (1,1'-(5,7-dihydroxy-2-oxo-4-phenyl-2H-chromene6,8-diyl-diethanone) (17). Yield 52\%; A white solid; m.p. $162-164{ }^{\circ} \mathrm{C}(\mathrm{Hex} / \mathrm{AcOEt}) ; \mathrm{IR}(\mathrm{KBr}): v=3467$, 1733, 1717, $1593 \mathrm{~cm}^{-1},{ }^{1} \mathrm{H}-\mathrm{NMR}\left(\mathrm{CDCl}_{3}\right) \delta 16.53(\mathrm{~s}, 1 \mathrm{H}), 15.92(\mathrm{~s}, 1 \mathrm{H}), 7.40(\mathrm{~m}, 3 \mathrm{H}), 7.28(\mathrm{~m}, 2 \mathrm{H}), 6.04$ (s, 1H), $2.95(\mathrm{~s}, 3 \mathrm{H}), 2.75(\mathrm{~s}, 3 \mathrm{H}) ;{ }^{13} \mathrm{C}-\mathrm{NMR}\left(\mathrm{CDCl}_{3}\right) \delta 33.4,33.5,102.8,106.3,112.4,126.9,127.8,128.5$, 138.9, 156.5, 158.0, 161.5, 170.2, 172.2, 203.9, 205.5. (EI) $m / z: 338\left(\mathrm{M}^{+} \mathrm{C}_{19} \mathrm{H}_{14} \mathrm{O}_{6}, 100\right), 323$ (94), 313 (48), 295(90), 277 (26), 139 (29).

Following the general procedure II using propionyl chloride, the crude reaction product was chromatographed and eluted with hexane/EtOAc, to yield $\mathbf{1 3}$ and $\mathbf{1 8 .}$

5,7-Dihydroxy-4-phenyl-8-propionyl-2H-chromen-2-one (13). Yield 28\%; A white solid; m.p. 216-218 ${ }^{\circ} \mathrm{C}$ (Hex:AcOEt); IR (KBr): $v=3218,3067,1693,1616,1592 \mathrm{~cm}^{-1},{ }^{1} \mathrm{H}-\mathrm{NMR}$ (MeOD) $\delta 7.37$ (m, 2H), 7.37 (m, 3H), $6.18(\mathrm{~s}, 1 \mathrm{H}), 5.99(\mathrm{~s}, 1 \mathrm{H}), 3.36(\mathrm{c}, J=7.3 \mathrm{~Hz}, 2 \mathrm{H}), 1.26(\mathrm{t}, J=7.3 \mathrm{~Hz}, 3 \mathrm{H}) ;{ }^{13} \mathrm{C}-\mathrm{NMR}(\mathrm{MeOD}) \delta 8.6$, 38.5, 100.2, 111.5, 127.6, 127.9, 128.6, 140.1, 158.3, 160.9, 162.6, 168.7, 206.7. (EI) $m / z: 310\left(\mathrm{M}^{+} \mathrm{C}_{18} \mathrm{H}_{14} \mathrm{O}_{5}\right.$, 36), 282 (18), 281 (100), $252(8), 171(7), 139$ (8). 
5,7-Dihydroxy-4-phenyl-6,8-dipropionyl-2H-chromen-2-one (18). Yield 49\%; A white solid; m.p. $152-154{ }^{\circ} \mathrm{C}$ (Hex:AcOEt); IR (KBr): $v=3468,3437,3067,2978,2937,2876 \mathrm{~cm}^{-1} ;{ }^{1} \mathrm{H}-\mathrm{NMR}\left(\mathrm{CDCl}_{3}\right) \delta 16.64(\mathrm{~s}, 1 \mathrm{H})$, $15.97(\mathrm{~s}, 1 \mathrm{H}), 7.40(\mathrm{~m}, 3 \mathrm{H}), 7.28(\mathrm{~m}, 2 \mathrm{H}), 6.03(\mathrm{~s}, 1 \mathrm{H}), 3.41(\mathrm{q}, J=7.3 \mathrm{~Hz}, 2 \mathrm{H}), 3.19(\mathrm{q}, J=6.7 \mathrm{~Hz}, 2 \mathrm{H})$,

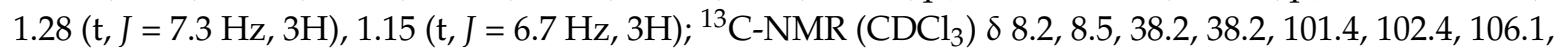
112.2, 126.9, 127.8, 128.5, 139.0, 156.7, 161.2, 169.9, 170.0, 172.0, 207.3, 208.7. (EI) m/z: $366\left(\mathrm{M}^{+} \mathrm{C}_{21} \mathrm{H}_{18} \mathrm{O}_{6}\right.$, 36), 338 (44), 337 (100), 319 (27), 308 (28), 281 (40), 178 (9), 138 (14).

Following the general procedure II using 3-methylbutanoyl chloride, the crude reaction product was chromatographed and eluted with hexane/EtOAc, to yield 9, 14, and 19.

5,7-Dihydroxy-6-(3-methylbutanoyl)-4-phenyl-2H-chromen-2-one (9). Yield 12\%; A white solid; m.p. 206-208 ${ }^{\circ} \mathrm{C}$ (Hex:AcOEt); IR (KBr): $v=3139,3111,2956,2928,2870,1689,1617,1580 \mathrm{~cm}^{-1}$; ${ }^{1} \mathrm{H}-\mathrm{NMR}$ $\left(\mathrm{CDCl}_{3}\right) \delta 15.79(\mathrm{~s}, 1 \mathrm{H}), 11.39(\mathrm{~s}, 1 \mathrm{H}), 7.52(\mathrm{~m}, 3 \mathrm{H}), 7.39(\mathrm{~m}, 2 \mathrm{H}), 6.63(\mathrm{~s}, 1 \mathrm{H}), 5.98(\mathrm{~s}, 1 \mathrm{H}), 2.90(\mathrm{~d}$, $J=6.3 \mathrm{~Hz}, 2 \mathrm{H}), 2.23(\mathrm{~m}, 1 \mathrm{H}), 0.92(\mathrm{~d}, J=6.3 \mathrm{~Hz}, 3 \mathrm{H}), 0.92(\mathrm{~d}, J=6.3 \mathrm{~Hz}, 3 \mathrm{H}) ;{ }^{13} \mathrm{C}-\mathrm{NMR}\left(\mathrm{CDCl}_{3}\right) \delta 22.5$, 22.5, 25.0, 53.0, 94.8, 101.4, 106.9, 111.3, 127.1, 127.4, 128.1, 139.0, 157.2, 159.6, 161.1, 163.7, 164.9, 207.3. (EI) $m / z: 338\left(\mathrm{M}^{+} \mathrm{C}_{20} \mathrm{H}_{18} \mathrm{O}_{5}, 10\right), 282$ (18), 281(100), 253 (3), 225(1), 171 (6), 139 (4).

5,7-Dihydroxy-8-(3-methylbutanoyl)-4-phenyl-2H-chromen-2-one (14). Yield 13\%; A white solid; m.p. 210-212 ${ }^{\circ} \mathrm{C}$ (Hex:AcOEt); IR (KBr): $v=3293,2959,2934,2874,2454,1745,1685,1620,1592 \mathrm{~cm}^{-1}$; ${ }^{1} \mathrm{H}-\mathrm{NMR}\left(\mathrm{CDCl}_{3}\right) \delta 14.14(\mathrm{~s}, 1 \mathrm{H}), 7.55(\mathrm{~m}, 3 \mathrm{H}), 7.43(\mathrm{~m}, 2 \mathrm{H}), 6.25(\mathrm{~s}, 1 \mathrm{H}), 6.01(\mathrm{~s}, 1 \mathrm{H}), 6.00(\mathrm{~s}, 1 \mathrm{H}), 3.17$ $(\mathrm{d}, J=6.3 \mathrm{~Hz}, 2 \mathrm{H}), 2.28(\mathrm{~m}, 1 \mathrm{H}), 1.05(\mathrm{~d}, J=6.3 \mathrm{~Hz}, 3 \mathrm{H}), 1.05(\mathrm{~d}, J=6.3 \mathrm{~Hz}, 3 \mathrm{H}) ;{ }^{13} \mathrm{C}-\mathrm{NMR}\left(\mathrm{CDCl}_{3}\right) \delta$ 22.7, 22.7, 25.5, 53.6, 101.6, 101.8, 104.9, 112.0, 127.5, 129.6, 130.3, 136.5, 154.1, 155.7, 158.7, 159.7, 168.8, 205.9. (EI) $m / z: 338\left(\mathrm{M}^{+} \mathrm{C}_{20} \mathrm{H}_{18} \mathrm{O}_{5}, 20\right), 323$ (12), 281 (100), 254 (9), 171(6), 141 (6).

5,7-Dihydroxy-6,8-bis(3-methylbutanoyl)-4-phenyl-2H-chromen-2-one or 1,1'-(5,7-dihydroxy-2-oxo-4-phenyl2H-chromene-6,8-diyl)bis(3-methylbutan-1-one) (19). Yield 50\%; A white solid; m.p. 148-150 ${ }^{\circ} \mathrm{C}$ (Hex:AcOEt); IR (KBr): $v=3469,3435,2959,2931,2871,1756,1618,1597 \mathrm{~cm}^{-1} ;{ }^{1} \mathrm{H}-\mathrm{NMR}\left(\mathrm{CDCl}_{3}\right) \delta 16.77(\mathrm{~s}, 1 \mathrm{H}), 16.09$ $(\mathrm{s}, 1 \mathrm{H}), 7.40(\mathrm{~m}, 3 \mathrm{H}), 7.28(\mathrm{~m}, 2 \mathrm{H}), 6.02(\mathrm{~s}, 1 \mathrm{H}), 3.18(\mathrm{~d}, J=6.7 \mathrm{~Hz}, 2 \mathrm{H}), 3.02(\mathrm{~d}, J=6.6 \mathrm{~Hz}, 2 \mathrm{H}), 2.27$ $(\mathrm{m}, 1 \mathrm{H}), 2.27(\mathrm{~m}, 1 \mathrm{H}), 1.06(\mathrm{~d}, J=6.7 \mathrm{~Hz}, 3 \mathrm{H}), 1.06(\mathrm{~d}, J=6.7 \mathrm{~Hz}, 3 \mathrm{H}), 0.95(\mathrm{~d}, J=6.6 \mathrm{~Hz}, 3 \mathrm{H}), 0.95(\mathrm{~d}$, $J=6.6 \mathrm{~Hz}, 3 \mathrm{H}) ;{ }^{13} \mathrm{C}-\mathrm{NMR}\left(\mathrm{CDCl}_{3}\right) \delta 22.7,22.7,22.7,22.7,24.9,25.8,53.3,53.3,101.5,102.6,106.4,112.2$, $126.9,127.8,128.4,139.1,156.6,158.0,161.8,170.3,172.4,206.6,207.9$. (EI) $m / z: 422\left(\mathrm{M}^{+} \mathrm{C}_{25} \mathrm{H}_{26} \mathrm{O}_{6}, 34\right)$, 418 (25), 394 (36), 381 (43), 365 (100), 347 (36), 337(32), 281 (49), 171 (25), 139 (36).

Following the general procedure II using heptanoyl chloride, the crude reaction product was chromatographed and eluted with hexane/EtOAc, to yield 10, 15, and 20.

6-Heptanoyl-5,7-dihydroxy-4-phenyl-2H-chromen-2-one (10). Yield 12\%; A white solid; m.p. 210-212 ${ }^{\circ} \mathrm{C}$ (Hex:AcOEt); IR (KBr): $v=3596,3254,3058,2954,2928,2856,1774,1688,1717,1593 \mathrm{~cm}^{-1} ;{ }^{1} \mathrm{H}-\mathrm{NMR}$ $\left(\mathrm{CDCl}_{3}\right) \delta 14.03(\mathrm{~s}, 1 \mathrm{H}), 10.11(\mathrm{~s}, 1 \mathrm{H}), 7.44(\mathrm{~m}, 3 \mathrm{H}), 7.35(\mathrm{~m}, 2 \mathrm{H}), 6.99(\mathrm{~s}, 1 \mathrm{H}), 5.99(\mathrm{~s}, 1 \mathrm{H}), 3.10(\mathrm{t}$, $J=6.7 \mathrm{~Hz}, 2 \mathrm{H}), 1.64(\mathrm{~m}, 4 \mathrm{H}), 1.24(\mathrm{~m}, 4 \mathrm{H}), 0.87(\mathrm{t}, J=6.7 \mathrm{~Hz}, 3 \mathrm{H}) ;{ }^{13} \mathrm{C}-\mathrm{NMR}\left(\mathrm{CDCl}_{3}\right) \delta 14.1,22.6,24.4$, 29.0, 31.7, 44.7, 95.9, 101.9, 107.1, 111.6, 127.4, 128.4, 128.9, 138.3, 157.7, 159.3, 161.8, 164.0, 164.8, 207.8. (EI) $m / z: 366\left(\mathrm{M}^{+} \mathrm{C}_{22} \mathrm{H}_{22} \mathrm{O}_{5}, 32\right), 351$ (14), 310 (30), (309 (100), 281 (82), 253(11), 171 (18), 139 (20).

8-Heptanoyl-5,7-dihydroxy-4-phenyl-2H-chromen-2-one (15). Yield 27\%; A white solid; m.p. 212-214 ${ }^{\circ} \mathrm{C}$ (Hex:AcOEt); IR (KBr): $v=3246,2951,2928,2868,2844 \mathrm{~cm}^{-1}, 1685,1637,1591 ;{ }^{1} \mathrm{H}-\mathrm{NMR}\left(\mathrm{CDCl}_{3}\right)$ $\delta 14.11(\mathrm{~s}, 1 \mathrm{H}), 7.54(\mathrm{~m}, 3 \mathrm{H}), 7.43(\mathrm{~m}, 2 \mathrm{H}), 6.25(\mathrm{~s}, 1 \mathrm{H}), 6.11(\mathrm{~s}, 1 \mathrm{H}), 6.00(\mathrm{~s}, 1 \mathrm{H}), 3.30(\mathrm{t}, \mathrm{J}=6.7 \mathrm{~Hz}$, 2H), $1.73(\mathrm{~m}, 4 \mathrm{H}), 1.33(\mathrm{~m}, 4 \mathrm{H}), 0.89(\mathrm{t}, J=6.7 \mathrm{~Hz}, 3 \mathrm{H}) ;{ }^{13} \mathrm{C}-\mathrm{NMR}\left(\mathrm{CDCl}_{3}\right) \delta 14.1,22.6,24.6,29.0,31.8$, $44.9,101.5,105.0,111.9,127.5,129.7,130.2,136.4,154.0,158.3,158.6,159.6,168.7,206.2$. (EI) $\mathrm{m} / z: 366$ $\left(\mathrm{M}^{+} \mathrm{C}_{22} \mathrm{H}_{22} \mathrm{O}_{5}, 44\right), 351$ (31), 309 (91), 281 (100), 267 (3), 253 (18), 171 (23), 139 (39).

6,8-Diheptanoyl-5,7-dihydroxy-4-phenyl-2H-chromen-2-one or 1,1'-(5,7-dihydroxy-2-oxo-4-phenyl-2H-chromene6,8-diyl)diheptan-1-one (20). Yield 50\%; A white solid; m.p. 164-166 ${ }^{\circ} \mathrm{C}$ (Hex:AcOEt); IR (KBr): $v=3458$, 34240, 2958, 2930, 2855, 1744, 1620, $1582 \mathrm{~cm}^{-1} ;{ }^{1} \mathrm{H}-\mathrm{NMR}\left(\mathrm{CDCl}_{3}\right) \delta 16.69(\mathrm{~s}, 1 \mathrm{H}), 16.02(\mathrm{~s}, 1 \mathrm{H}), 7.40(\mathrm{~m}$, $3 \mathrm{H}), 7.28(\mathrm{~m}, 2 \mathrm{H}), 6.02(\mathrm{~s}, 1 \mathrm{H}), 3.33(\mathrm{t}, J=7.3 \mathrm{~Hz}, 2 \mathrm{H}), 3.14(\mathrm{t}, J=7.3 \mathrm{~Hz}, 2 \mathrm{H}), 1.76(\mathrm{~m}, 4 \mathrm{H}), 1.64(\mathrm{~m}, 4 \mathrm{H})$, $1.32(\mathrm{~m}, 4 \mathrm{H}), 1.32(\mathrm{~m}, 4 \mathrm{H}), 0.90(\mathrm{~m}, 3 \mathrm{H}), 0.90(\mathrm{~m}, 3 \mathrm{H}) ;{ }^{13} \mathrm{C}-\mathrm{NMR}\left(\mathrm{CDCl}_{3}\right) \delta$ 14.0, 14.0, 22.6, 22.6, 24.3, 24.8, 29.0, 29.0, 31.6, 31.8, 44.8, 44.8, 101.4, 102.5, 106.2, 112.3, 127.0, 127.8, 128.5, 139.1, 156.6, 158.0, 
161.2, 170.1, 172.2, 207.0, 208.4. (EI) $m / z: 478\left(\mathrm{M}^{+} \mathrm{C}_{29} \mathrm{H}_{34} \mathrm{O}_{6}, 24\right), 421$ (34), 393 (100), 323 (38), 293(52), $171(20), 139$ (14).

Following the general procedure II using benzoyl chloride, the crude reaction product was chromatographed and eluted with hexane/EtOAc, to 11 and 16.

6-Benzoyl-5,7-dihydroxy-4-phenyl-2H-chromen-2-one (11). Yield 18\%; A white solid; m.p. $245-247{ }^{\circ} \mathrm{C}$ (AcOEt). The spectral data (IR, ${ }^{1} \mathrm{H}-\mathrm{NMR}$ and $\left.{ }^{13} \mathrm{C}-\mathrm{NMR}\right)$ were quite comparable with the data reported in $[46,48]$.

8-Benzoyl-5,7-dihydroxy-4-phenyl-2H-chromen-2-one (16). Yield 34\%; A white solid; m.p. $253-256{ }^{\circ} \mathrm{C}$ (AcOEt). The spectral data (IR, ${ }^{1} \mathrm{H}-\mathrm{NMR}$ and $\left.{ }^{13} \mathrm{C}-\mathrm{NMR}\right)$ were quite comparable with the data reported in $[50,51]$.

\subsection{General Procedures III: Synthesis of Compounds $\mathbf{2 2 - 2 8}$}

To a mixture of $\mathrm{POCl}_{3}(10 \mathrm{mmol})$ and $\mathrm{BF}_{3}-\mathrm{Et}_{2} \mathrm{O}(20 \mathrm{mmol})$ at $0{ }^{\circ} \mathrm{C}$, appropriated cinnamic acid ( $5 \mathrm{mmol}$ ) was added and the reaction mixture stirred for $15 \mathrm{~min}$ at $0{ }^{\circ} \mathrm{C}$. Phenol $(5 \mathrm{mmol}$ ) was added to the above reaction mixture in small portions and stirring continued at $25-28^{\circ} \mathrm{C}$ for $4-12 \mathrm{~h}$. The reaction mixture was poured on to ice-water; sodium acetate $(1 \mathrm{~g})$ was added and the mixture was warmed on a water bath for $2 \mathrm{~min}$. It was cooled, extracted with ethyl acetate $(2 \times 150 \mathrm{~mL})$, washed with water $(150 \mathrm{~mL})$, dried, and the solvent removed under reduced pressure to obtain the crude product, which was purified by column chromatography using acetone-chloroform as eluent to afford pure 4-phenyldihydro-coumarins $22-28$ in 60\%-75\% yields.

4-(4-Methoxyphenyl)chroman-2-one (22). This was prepared from $p$-methoxycinnamic acid and phenol using the general procedure III. Yield $62 \%$; A white solid; m.p. $160-162{ }^{\circ} \mathrm{C}\left(\mathrm{CH}_{2} \mathrm{Cl}_{2} / \mathrm{MeOH}\right) ; \mathrm{IR}(\mathrm{KBr})$ : $v=2943,2927,2907,2833,1832,1717,1701,1608 \mathrm{~cm}^{-1} ;{ }^{1} \mathrm{H}-\mathrm{NMR}\left(\mathrm{CDCl}_{3}\right) \delta 7.31(\mathrm{br} \mathrm{d}, J=8.1 \mathrm{~Hz}$, $1 \mathrm{H}), 7.12(\mathrm{~d}, J=8.2 \mathrm{~Hz}, 2 \mathrm{H}), 7.07(\mathrm{br} \mathrm{d}, J=8.2 \mathrm{~Hz}, 1 \mathrm{H}), 6.97(\mathrm{~m}, 2 \mathrm{H}), 6.87(\mathrm{~d}, J=8.2 \mathrm{~Hz}, 3 \mathrm{H}), 4.30(\mathrm{t}$, $J=7.3 \mathrm{~Hz}, 1 \mathrm{H}), 3.79(\mathrm{~s}, 3 \mathrm{H}), 3.08(\mathrm{dd}, J=7.3 \mathrm{~Hz}, 15.7 \mathrm{~Hz}, 1 \mathrm{H}), 2.96(\mathrm{dd}, J=7.3,15.7 \mathrm{~Hz}, 2 \mathrm{H}) ;{ }^{13} \mathrm{C}-\mathrm{NMR}$ $\left(\mathrm{CDCl}_{3}\right) \delta 37.2,40.0,55.3,114.5$ (2C), 117.1, 124.7, 126.3, 128.3, 128.6 (3C), 132.2, 151.7, 159.0, 167.8. (EI) m/z: $254\left(\mathrm{M}^{+} \mathrm{C}_{16} \mathrm{H}_{14} \mathrm{O}_{3}, 65\right), 226$ (14), 212 (15), 211 (72), 197 (22), 182 (15), 181 (100), 168 (13), 139 (12).

4-(3,4-Dimethoxyphenyl)-7-hydroxychroman-2-one (23). This was prepared from 3,4-dimethoxycinnamic acid and resorcinol as described in the general procedure III. Yield $67 \%$; A white solid; m.p. $167-169^{\circ} \mathrm{C}$ $\left(\mathrm{CHCl}_{3} / \mathrm{MeOH}\right) ; \mathrm{IR}(\mathrm{KBr}): v=3434,2960,2936,1762,1624,1595 \mathrm{~cm}^{-1} ;{ }^{1} \mathrm{H}-\mathrm{NMR}\left(\mathrm{CDCl}_{3}\right) \delta 6.83(\mathrm{~d}$, $J=7.7 \mathrm{~Hz}, 1 \mathrm{H}), 6.68(\mathrm{dd}, J=7.7,2.4 \mathrm{~Hz}, 1 \mathrm{H}), 6.68(\mathrm{~d}, J=2.4 \mathrm{~Hz}, 1 \mathrm{H}), 6.67(\mathrm{~d}, J=7.7 \mathrm{~Hz}, 1 \mathrm{H}), 6.66$ $(\mathrm{s}, 1 \mathrm{H}), 6.59(\mathrm{dd}, J=8.2,2.4 \mathrm{~Hz}, 1 \mathrm{H}), 6.46(\mathrm{br} \mathrm{s}, 1 \mathrm{H}), 4.21(\mathrm{t}, J=7.3 \mathrm{~Hz}, 1 \mathrm{H}), 3.85(\mathrm{~s}, 3 \mathrm{H}), 3.81(\mathrm{~s}, 3 \mathrm{H})$, $3.06(\mathrm{dd}, J=7.3 \mathrm{~Hz}, 14.9 \mathrm{~Hz}, 1 \mathrm{H}), 2.95(\mathrm{dd}, J=7.3,14.9 \mathrm{~Hz}, 1 \mathrm{H}) ;{ }^{13} \mathrm{C}-\mathrm{NMR}\left(\mathrm{CDCl}_{3}\right) \delta 37.5,39.6,55.9$, $55.9,104.2,110.6,111.6,112.1,117.5,119.8,129.1,133.2,148.3,149.3,152.1,156.5,168.7$. (EI) $\mathrm{m} / \mathrm{z}: 300$ $\left(\mathrm{M}^{+} \mathrm{C}_{17} \mathrm{H}_{16} \mathrm{O}_{5}, 100\right), 269$ (14), 257 (36), 243 (26), 227 (81), 190 (14), 139 (8).

4-(4-Hydroxyphenyl)-7-methoxychroman-2-one (24). This was prepared from $p$-coumaric acid and resorcinol as described in the general procedure III. Yield $68 \%$; A white solid; m.p. $169-171{ }^{\circ} \mathrm{C}\left(\mathrm{CHCl}_{3} / \mathrm{MeOH}\right)$; IR (KBr): $v=3436,2938,2904,2840,1762,1615 \mathrm{~cm}^{-1} ;{ }^{1} \mathrm{H}-\mathrm{NMR}\left(\mathrm{CDCl}_{3}\right) \delta 6.98(\mathrm{~d}, J=8.3 \mathrm{~Hz}, 2 \mathrm{H}), 6.89$ $(\mathrm{d}, J=8.3 \mathrm{~Hz}, 1 \mathrm{H}), 6.77(\mathrm{~d}, J=8.3 \mathrm{~Hz}, 2 \mathrm{H}), 6.66(\mathrm{~d}, J=2.4 \mathrm{~Hz}, 1 \mathrm{H}), 6.64(\mathrm{dd}, J=8.3,2.4 \mathrm{~Hz}, 1 \mathrm{H}), 5.54(\mathrm{br}$ $\mathrm{s}, 1 \mathrm{H}), 4.22(\mathrm{t}, J=6.8 \mathrm{~Hz}, 1 \mathrm{H}), 3.80(\mathrm{~s}, 3 \mathrm{H}), 3.05(\mathrm{dd}, J=6.8,15.1 \mathrm{~Hz}, 1 \mathrm{H}), 2.93(\mathrm{dd}, J=6.8,15.1 \mathrm{~Hz}, 1 \mathrm{H})$; ${ }^{13} \mathrm{C}-\mathrm{NMR}\left(\mathrm{CDCl}_{3}\right) \delta 37.4,39.3,55.6,102.4,110.7,115.6,115.6,118.0,128.7,128.7,128.8,132.6,152.3$, 155.0, 159.9, 168.1. (EI) $m / z: 270\left(\mathrm{M}^{+} \mathrm{C}_{16} \mathrm{H}_{14} \mathrm{O}_{4}, 38\right), 242$ (17), 228 (10), 227 (100), 211 (40), 184 (15), 128 (18).

5,7-Dichloro-4-phenylchroman-2-one (25). This was prepared from cinnamic acid and 3,5-dichorophenol as described in the general procedure III. Yield $70 \%$; A white solid; m.p. $230-232{ }^{\circ} \mathrm{C}\left(\mathrm{CHCl}_{3}\right)$; IR (KBr): $v=3077,1713,1599,1567 \mathrm{~cm}^{-1},{ }^{1} \mathrm{H}-\mathrm{NMR}\left(\mathrm{CDCl}_{3}\right) \delta 7.27(\mathrm{~m}, 3 \mathrm{H}), 7.22(\mathrm{~d}, J=1.9 \mathrm{~Hz}, 1 \mathrm{H}), 7.11$ $(\mathrm{d}, J=1.9 \mathrm{~Hz}, 1 \mathrm{H}), 7.06(\mathrm{~m}, 2 \mathrm{H}), 4.64(\mathrm{dd}, J=5.4,3.4 \mathrm{~Hz}, 1 \mathrm{H}), 3.10(\mathrm{dd}, J=3.4,12.2 \mathrm{~Hz}, 1 \mathrm{H}), 3.04(\mathrm{dd}$, 
$J=5.4,12.2 \mathrm{~Hz}, 1 \mathrm{H}) ;{ }^{13} \mathrm{C}-\mathrm{NMR}\left(\mathrm{CDCl}_{3}\right) \delta 36.7,38.5,116.5,122.2,125.6,126.7,126.7,127.9,129.2,129.2$, 134.5, 138.9, 152.9, 165.7. (EI) $m / z: 293\left(\mathrm{M}^{+} \mathrm{C}_{15} \mathrm{H}_{10} \mathrm{O}_{2} \mathrm{Cl}_{2}, 36\right), 291$ (59), 276 (23), 274 (36), 256 (13), 251 (64), 249 (100), 215 (19), 152 (33).

8-(4-Hydroxy-3,5-dimethoxyphenyl)-7,8-dihydro-[1,3]dioxolo[4,5-g]chromen-6-one (26). This was prepared from 4-hydroxy-3,5-dimethoxycinnamic acid and sesamol as described in the general procedure III. Yield 69\%; A white solid; m.p. 162-164 ${ }^{\circ} \mathrm{C}$ (eter); IR (KBr): $v=3458,3023,3007,2956,2930,2913,2836$, 1742, 1627, $1609 \mathrm{~cm}^{-1} ;{ }^{1} \mathrm{H}-\mathrm{NMR}\left(\mathrm{CDCl}_{3}\right) \delta 6.65(\mathrm{~s}, 1 \mathrm{H}), 6.41(\mathrm{~s}, 1 \mathrm{H}), 6.36(\mathrm{~s}, 2 \mathrm{H}), 5.96(\mathrm{~s}, 2 \mathrm{H}), 5.52$ (br s, $1 \mathrm{H}), 4.13(\mathrm{t}, J=7.3 \mathrm{~Hz}, 1 \mathrm{H}), 3.84(\mathrm{~s}, 3 \mathrm{H}), 3.84(\mathrm{~s}, 3 \mathrm{H}), 3.09(\mathrm{dd}, J=7.3,15.8 \mathrm{~Hz}, 1 \mathrm{H}), 2.92(\mathrm{dd}, J=7.3$, $15.8 \mathrm{~Hz}, 1 \mathrm{H}) ;{ }^{13} \mathrm{C}-\mathrm{NMR}\left(\mathrm{CDCl}_{3}\right) \delta 37.2,40.8,56.4,56.4,99.1,101.7,104.2,104.2,107.2,118.2,131.5,134.2$, 144.5, 146.1, 147.5, 147.5, 147.5, 167.8. (EI) $m / z: 344\left(\mathrm{M}^{+} \mathrm{C}_{18} \mathrm{H}_{16} \mathrm{O}_{7}, 100\right), 326$ (13), 295 (14), 271 (82), 256 (21), 167 (37), 133 (12).

8-(3,4,5-Trimethoxyphenyl)-7,8-dihydro-[1,3]dioxolo[4,5-g]chromen-6-one (27). This was prepared from 3,4,5-trimethoxycinnamic acid and sesamol as described in the general procedure III. Yield 61\%; A white solid; m.p. $162-164{ }^{\circ} \mathrm{C}$ (diethyl ether); IR (KBr): $v=3023,3007,2956,2930,2913,2836,1742$, 1627, 1609, $1584 \mathrm{~cm}^{-1},{ }^{1} \mathrm{H}-\mathrm{NMR}\left(\mathrm{CDCl}_{3}\right) \delta 6.66(\mathrm{~s}, 1 \mathrm{H}), 6.43(\mathrm{~s}, 1 \mathrm{H}), 6.35(\mathrm{~s}, 2 \mathrm{H}), 5.96(\mathrm{~s}, 2 \mathrm{H}), 4.15(\mathrm{t}$, $J=6.8 \mathrm{~Hz}, 1 \mathrm{H}), 3.83(\mathrm{~s}, 3 \mathrm{H}), 3.81(\mathrm{~s}, 6 \mathrm{H}), 3.05(\mathrm{dd}, J=6.8,16.1 \mathrm{~Hz}, 1 \mathrm{H}), 2.92(\mathrm{dd}, J=6.8,16.1 \mathrm{~Hz}, 1 \mathrm{H})$; ${ }^{13} \mathrm{C}-\mathrm{NMR}\left(\mathrm{CDCl}_{3}\right) \delta 37.1,41.0,56.1,56.1,60.8,99.2,101.8,104.4,104.5,107.2,117.8,136.1,136.1,137.5$, 144.5, 146.1, 147.6, 153.7, 167.6. (EI) $\mathrm{m} / z$ : $358\left(\mathrm{M}^{+} \mathrm{C}_{19} \mathrm{H}_{18} \mathrm{O}_{7}, 100\right), 325$ (29), 315 (21), 285 (83), 241 (27), 215 (35), 181 (81), 133 (38).

8-Hydroxy-7-methoxy-4-(3,4,5-trimethoxyphenyl)chroman-2-one (28). This was prepared from 3,4,5-trimethoxycinnamic acid and 3-methoxybenzene-1,2-diol as described in the general procedure III. Yield 60\%; A white solid; m.p. $164-166{ }^{\circ} \mathrm{C}\left(\mathrm{CHCl}_{3} / \mathrm{MeOH}\right)$; IR (KBr): $v=3309,3001,2951,2841$, $1759,1629,1588 \mathrm{~cm}^{-1} ;{ }^{1} \mathrm{H}-\mathrm{NMR}\left(\mathrm{CDCl}_{3}\right) \delta 6.64(\mathrm{~d}, J=8.5 \mathrm{~Hz}, 1 \mathrm{H}), 6.48(\mathrm{~d}, J=8.5 \mathrm{~Hz}, 1 \mathrm{H}), 6.37(\mathrm{~s}, 2 \mathrm{H})$, $5.73(\mathrm{~s}, 1 \mathrm{H}), 4.24(\mathrm{t}, J=7.3 \mathrm{~Hz}, 1 \mathrm{H}), 3.90(\mathrm{~s}, 3 \mathrm{H}), 3.83(\mathrm{~s}, 3 \mathrm{H}), 3.80(\mathrm{~s}, 6 \mathrm{H}), 3.09(\mathrm{dd}, J=7.3,14.1 \mathrm{~Hz}, 1 \mathrm{H})$, $2.97(\mathrm{dd}, J=7.3,14.1 \mathrm{~Hz}, 1 \mathrm{H}) ;{ }^{13} \mathrm{C}-\mathrm{NMR}\left(\mathrm{CDCl}_{3}\right) \delta 37.2,40.8,56.4,56.4,56.4,60.8,104.6,104.6,107.0$, $117.9,119.2,133.8,136.2,137.4,139.4,147.2,153.6,153.6,166.8$. (EI) $m / z: 360\left(\mathrm{M}^{+} \mathrm{C}_{19} \mathrm{H}_{20} \mathrm{O}_{7}, 100\right), 345$ (22), 327 (35), 317 (19), 287 (99), 272 (24), 217 (17), 181 (31), 173 (22).

\subsection{Antiviral Activity Assays}

The anti-HIV activity of these neoflavonoids on Tat and NF-kB functions has been evaluated. To this aim, we have used two stably transfected cell lines. The previously described 5.1 cell line [55] is a Jurkat-derived clone stably transfected with a plasmid containing the luciferase gene under the control of HIV-LTR. In this cell clone, activation with TNF $\alpha$ induces NF- $\mathrm{B}$ activation and subsequent HIV-1 expression. We have also analysed the anti-HIV activity in HeLa-Tat-Luc cells, in which the HIV-1 LTR is directly activated by the HIV-1 Tat protein. A compound was considered active in one assay if it inhibited the target function by more than 50\% (NF- $\mathrm{kB}$ ) or 30\% (Tat) at either 25 or $50 \mu \mathrm{M}$ concentration. The active compounds were submitted for further evaluation through a HeLa-Tet-ON assay, as previously described [56]. In the Hela-Tet-ON cells the luciferase expression is under control of an artificial promoter that can be activated by tetracycline. Therefore, compounds that inhibit tetracycline-induced luciferase activity were considered non-specific for luciferase-based anti-HIV assays.

Cell viability was evaluated in non-infected treated cultures following the same protocol as in the recombinant virus assay and measuring cell toxicity with a classical MTT assay. $\mathrm{IC}_{50}$ were calculated using GraphPad Prism software (non-linear regression, log (inhibitor) vs. response).

\section{Conclusions}

A series of twenty-eight neoflavonoids have been synthesized and evaluated against HIV-1 in vitro. Ten 4-phenylchromen-2-one derivatives displayed HIV specific transcriptional inhibition and five displayed nonspecific mechanisms of action. The heptanoylchromen-one $\mathbf{1 0}$ was the more potent 
Tat antagonist, while compound $\mathbf{1 4}$ showed high inhibition of the NF-kB pathway. A preliminary SAR analysis established that the presence of the acyl group is essential for the anti HIV in both targets.

Supplementary Materials: The following are available online at http:/ /www.mdpi.com/1420-3049/22/2/321/s1, Figure S1: Spectroscopic data of neoflavonoid derivatives 3-10, 12-15, 17-28.

Acknowledgments: This research is part of the following projects funded by the Spanish Ministry of Economy and Competitiveness and Instituto de Salud Carlos III (PI16/CIII/034); the Spanish AIDS Research Network (RD16CIII/0002/0001) that is included in the Spanish I+D+I Plan and is co-financed by ISCIII-Subdirección General de Evaluacion and European Funding for Regional Development (FEDER), Acknowledgements are also due to the University of Panama, and to the National Secretariat of Science, Technology and Innovation (SENACYT) of Panama for SNI distinguished scientist stimulus award to MPG.

Author Contributions: The authors of these research have participated as follows: “José Luis López-Pérez, Esther Del Olmo and Arturo San Feliciano" conceived and designed structures and synthesis project; "Dionisio A. Olmedo" performed all the synthetic experiments; "José Luis López-Pérez and Dionisio A. Olmedo" interpreted the results, discussed the experimental data and prepared the manuscript; "Rocío Sancho, Eduardo Muñoz, Luis M. Bedoya and José Alcamí" conducted the biological assay and provided the experimental procedure and results; “Dionisio A. Olmedo, José Luis López-Pérez, Arturo San Feliciano, Luis M. Bedoya and Mahabir P. Gupta contributed in overall redaction and revision of the manuscript.

Conflicts of Interest: The authors declare no conflict of interest.

\section{References}

1. UNAIDS. The Joint United Nations Programme on HIV/AIDS. Report on the World Statistic the People Living with HIV. 2015. Available online: http://aidsinfo.unaids.org/ (accessed on 21 August 2016).

2. Piot, P.; Bartos, M.; Ghys, P.D.; Walker, N.; Schwartlander, B. The global impact of HIV / AIDS. Nature 2001, 410, 968-973. [CrossRef]

3. McNicholl, I.R.; McNicholl, J.J. On the horizon: Promising investigational antiretroviral agents. Curr. Pharm. Des. 2006, 12, 1091-1103. [CrossRef] [PubMed]

4. Wainberg, M.A.; Jeang, K.T. 25 years of HIV-1 research-Progress and perspectives. BMC Med. 2008, 6. [CrossRef] [PubMed]

5. Barouch, D.H. Challenges in the development of an HIV-1 vaccine. Nature 2008, 455, 613-619. [CrossRef] [PubMed]

6. Adamson, C.S.; Freed, E.O. Recent progress in antiretrovirals-Lessons from resistance. Drug Discov. Today 2008, 13, 424-432. [CrossRef] [PubMed]

7. Rabson, A.B.; Lin, H.C. NF-kB and HIV: Linking viral and immune activation. Adv. Pharmacol. 2000, 48, 161-207. [PubMed]

8. Gatignol, A.; Duarte, M.; Daviet, L.; Chang, Y.N.; Jeang, K.T. Sequential steps in Tat trans-activation of HIV-1 mediated through cellular DNA, RNA, and protein binding factors. Gene Expr. 1996, 5, 217-228. [PubMed]

9. Chen, B.K.; Feinberg, M.B.; Baltimore, D. The $\mathrm{kB}$ sites in the human immunodeficiency virus type 1 long terminal repeat enhance virus replication yet are not absolutely required for viral growth. J. Virol. 1997, 71, 5495-5504.

10. Greene, W.C. The molecular biology of human immunodeficiency virus type 1 infection. N. Engl. J. Med. 1991, 324, 308-317. [PubMed]

11. Alcamí, J.; Lain de Lera, T.; Folgueira, L.; Pedraza, M.A.; Jacque, J.M.; Bachelerie, F.; Noriega, A.R.; Hay, R.T.; Harrich, D.; Gaynor, R.B. Absolute dependence on kappa B responsive elements for initiation and Tat-mediated amplification of HIV transcription in blood CD4 T lymphocytes. EMBO J. 1995, 14, 1552-1560. [PubMed]

12. Stevenson, M. Tat's seductive side. Nat. Med. 2003, 9, 163-164. [CrossRef] [PubMed]

13. Yeni, P.G.; Hammer, S.M.; Carpenter, C.C.; Cooper, D.A.; Fischl, M.A.; Gatell, J.M.; Gazzard, B.G.; Hirsch, M.S.; Jacobsen, D.M.; Katzenstein, D.A.; et al. Antiretroviral treatment for adult HIV infection in 2002: Updated recommendations of the International AIDS Society-USA Panel. JAMA 2002, 288, 222-235. [CrossRef] [PubMed]

14. Karin, M.; Yamamoto, Y.; Wang, Q.M. The IKK NF-кB system: A treasure trove for drug development. Nat. Rev. Drug Discov. 2004, 3, 17-26. [CrossRef] [PubMed]

15. Ferchichi, L.; Derbre, S.; Mahmood, K.; Toure, K.; Guilet, D.; Litaudon, M.; Awang, K.; Hadi, A.H.A.; Le Ray, A.M.; Richomme, P. Bioguided fractionation and isolation of natural inhibitors of advanced glycation end-products (AGEs) from Calophyllum flavoramulum. Phytochemistry 2012, 78, 98-106. [CrossRef] [PubMed] 
16. Brenzan, M.A.; Nakamura, C.V.; Dias Filho, B.P.; Ueda-Nakamura, T.; Young, M.C.M.; García Cortez, D.A. Antileishmanial activity of crude extract and coumarin from Calophyllum brasiliense leaves against Leishmania amazonensis. Parasitol. Res. 2007, 101, 715-722. [CrossRef] [PubMed]

17. Guilet, D.; Helesbeux, J.-J.; Seraphin, D.; Sevenet, T.; Richomme, P.; Bruneton, J. Novel cytotoxic 4-phenylfuranocoumarins from Calophyllum dispar. J. Nat. Prod. 2001, 64, 563-568. [CrossRef] [PubMed]

18. Guilet, D.; Seraphin, D.; Rondeau, D.; Richomme, P.; Bruneton, J. Cytotoxic coumarins from Calophyllum dispar. Phytochemistry 2001, 58, 571-575. [CrossRef]

19. Kashman, Y.; Gustafson, K.R.; Fuller, R.W.; Cardellina, J.H.; McMahon, J.B.; Currens, M.J.; Buckheit, R.W.; Hughes, S.H.; Cragg, G.M.; Boyd, M.R. HIV inhibitory natural products. Part 7. The calanolides, a novel HIV-inhibitory class of coumarin derivatives from the tropical rainforest tree, Calophyllum lanigerum. J. Med. Chem. 1992, 35, 2735-2743. [CrossRef] [PubMed]

20. Patil, A.D.; Freyer, A.J.; Eggleston, D.S.; Haltiwanger, R.C.; Bean, M.F.; Taylor, P.B.; Caranfa, M.J.; Breen, A.L.; Bartus, H.R. The inophyllums, novel inhibitors of HIV-1 reverse transcriptase isolated from the Malaysian tree, Calophyllum inophyllum Linn. J. Med. Chem. 1993, 36, 4131-4138. [CrossRef] [PubMed]

21. Games, D.E. Identification of 4-phenyl and 4-alkylcoumarins in Mammea americana L., Mammea africana G. Don and Calophyllum inophyllum by gas chromatography. Mass Spectrometry. Tetrahedron Lett. 1972, 13, 3187-3190. [CrossRef]

22. Reutrakul, V.; Leewanich, P.; Tuchinda, P.; Pohmakotr, M.; Jaipetch, T.; Sophasan, S.; Santisuk, T. Cytotoxic coumarins from Mammea harmandii. Planta Med. 2003, 69, 1048-1051. [PubMed]

23. Prachyawarakorn, V.; Mahidol, C.; Ruchirawat, S. NMR study of seven coumarins from Mammea siamensis. Pharm. Biol. 2000, 38, 58-62. [CrossRef] [PubMed]

24. Crombie, L.; Jones, R.C.F.; Palmer, C.J. Synthesis of the mammea coumarins. Part 1. The coumarins of the mammea A, B, and C series. J. Chem. Soc. Perkin Trans. 1 1987, 317-331. [CrossRef]

25. Carpenter, I.; McGarry, E.J.; Scheinmann, F. Extractives from Guttiferae. Part XXI: The isolation and structure of nine coumarins from the bark of Mammea africana G. Don. J. Chem. Soc. C. 1971, 3783-3790. [CrossRef]

26. Crombie, L.; Games, D.E.; McCormick, A. Extractives of Mammea americana L. Part II. The 4-phenylcoumarins isolation and structure of Mammea A/AA, A/A cyclo D, A/BA, A/AB, and A/BB. J. Chem. Soc. C. 1967, 2255-2260. [CrossRef]

27. Rouger, C.; Derbré, S.; Charreau, B.; Pabois, A.; Cauchy, T.; Litaudon, M.; Awang, K.; Richomme, P. Lepidotol A from Mesua lepidota Inhibits Inflammatory and Immune Mediators in Human Endothelial Cells. J. Nat. Prod. 2015, 78, 2187-2197. [CrossRef] [PubMed]

28. Cheng Lian, G.; Sin The, S.; Hui Mah, S.; Rahmani, M.; Taufiq-Yap, Y.H.; Awang, K. A Novel Cyclodione Coumarin from the Stem Bark of Mesua beccariana. Molecules 2011, 16, 7249-7255.

29. Awang, K.; Chan, G.; Litaudon, M.; Ismail, N.H.; Martin, M.-T.; Gueritte, F.O. 4-Phenylcoumarins from Mesua elegans with acetylcholinesterase inhibitory activity. Bioorg. Med. Chem. 2010, 18, 7873-7877. [CrossRef] [PubMed]

30. Verotta, L.; Lovaglio, E.; Vidari, G.; Finzi, P.V.; Neri, M.G.; Raimondi, A.; Parapini, S.; Taramelli, D.; Riva, A.; Bombardelli, E. 4-Alkyl- and 4-phenylcoumarins from Mesua ferrea as promising multidrug resistant antibacterials. Phytochemistry 2004, 65, 2867-2879. [CrossRef] [PubMed]

31. Morel, C.; Dartiguelongue, C.; Youhana, T.; Oger, J.M.; Seraphin, D.; Duval, O.; Richomme, P.; Bruneton, J. New coumarins from Mesua racemosa: Isolation and synthesis. Heterocycles 1999, 51, 2183-2191.

32. Morel, C.; Guilet, D.; Oger, J.M.; Seraphin, D.; Sevenet, T.; Wiart, C.; Hadi, A.H.A.; Richomme, P.; Bruneton, J. 6-Acylcoumarins from Mesua racemosa. Phytochemistry 1999, 50, 1243-1247. [CrossRef]

33. Bala, K.R.; Seshadri, T.R. Isolation and synthesis of some coumarin components of Mesua ferrea seed oil. Phytochemistry 1971, 10, 1131-1134. [CrossRef]

34. Cruz, F.G.; Moreira, L.d.M.; Santos, N.A.S.; Guedes, M.L.S. Additional Coumarins from Kielmeyera reticulate. J. Braz. Chem. Soc. 2002, 13, 704-707. [CrossRef]

35. Cruz, F.G.; da Silva-Neto, J.T.; Guedes, M.L.S. Xanthones and Coumarins from Kielmeyera lathrophyton. J. Braz. Chem. Soc. 2001, 12, 117-122. [CrossRef]

36. Gramacho, R.d.S.; Nagem, T.J.; de Oliveira, T.T.; de Queiroz, M.E.L.R.; Neves, A.A.; Saddi, N. Phenylcoumarins from Kielmeyera elata. Phytochemistry 1999, 51, 579-581. [CrossRef]

37. Cruz, F.G.; Santos, N.A.S.; David, J.M.; Guedes, M.L.S.; Chávez, J.P. Coumarins from Kielmeyera argentea. Phytochemistry 1998, 48, 703-706. [CrossRef] 
38. Cruz, F.G.; Moreira, L.M.; David, J.M.; Guedes, M.L.S.; Chávez, J.P. Coumarins from Kielmeyera reticulata. Phytochemistry 1998, 47, 1363-1366.

39. López-Pérez, J.L.; Olmedo, D.A.; del Olmo, E.; Vásquez, Y.; Solís, P.N.; Gupta, M.P.; San Feliciano, A. Cytotoxic 4-phenylcoumarins from the leaves of Marila pluricostata. J. Nat. Prod. 2005, 68, 369-373. [CrossRef] [PubMed]

40. Ishikawa, T. Chemistry of Anti HIV-1 Active Calophyllum Coumarins. J. Synth. Org. Chem. Jpn. 1998, 56, 116-124. [CrossRef]

41. Chiang, C.C.; Mouscadet, J.F.; Tsai, H.J.; Liu, C.T.; Hsu, L.Y. Synthesis and HIV-1 integrase inhibition of novel bis- or tetra-coumarin analogues. Chem. Pharm. Bull. 2007, 55, 1740-1743. [CrossRef] [PubMed]

42. Márquez, N.; Sancho, R.; Bedoya, L.M.; Alcamí, J.; López-Pérez, J.L.; San Feliciano, A.; Fiebich, B.L.; Muñoz, E. Mesuol, a natural occurring 4-phenylcoumarin, inhibits HIV-1 replication by targeting the NF- $\mathrm{B}$ pathway. Antivir. Res. 2005, 66, 137-145. [CrossRef] [PubMed]

43. Bedoya, L.M.; Beltrán, M.; Sancho, R.; Olmedo, D.A.; Sánchez-Palomino, S.; Olmo, E.; López-Pérez, J.L.; Muñoz, E.; San Feliciano, A.; Alcamí, J. 4-Phenylcoumarins as HIV transcription inhibitors. Bioorg. Med. Chem. Lett. 2005, 15, 4447-4450. [CrossRef] [PubMed]

44. Krishna, C.; Bhargavi, M.V.; Rao, C.P.; Krupadanama, D. Synthesis and antimicrobial assessment of novel coumarins featuring 1,2,4-oxadiazole. Med. Chem. Res. 2015, 24, 3743-3751. [CrossRef]

45. Chin, Y.P.; Huang, W.J.; Hsu, F.L.; Lin, Y.L.; Lin, M.H. Synthesis and evaluation of antibacterial activities of 5,7-Dihydroxycoumarin derivatives. Arch. Pharm. 2011, 344, 386-393. [CrossRef] [PubMed]

46. Hwang, C.H.; Jaki, B.U.; Klein, L.L.; Lankin, D.C.; McAlpine, J.B.; Napolitano, J.G.; Fryling, N.A.; Franzblau, S.G.; Cho, S.H.; Stamets, P.E.; et al. Chlorinated Coumarins from the Polypore Mushroom Fomitopsis officinalis and Their Activity against Mycobacterium tuberculosis. J. Nat. Prod. 2013, 76, 1916-1922. [CrossRef] [PubMed]

47. Lin, C.M.; Huang, S.T.; Lee, F.W.; Kuo, H.S.; Lin, M.H. 6-Acyl-4-aryl/alkyl-5,7-dihydroxycoumarins as anti-inflammatory agents. Bioorg. Med. Chem. 2006, 14, 4402-4409. [CrossRef] [PubMed]

48. Del Olmo, E. Final Report Project X.11. Iberoamerican Program of Science and Technology for Development: Madrid, Spain, 2004; (unpublished results).

49. Cao, S.G.; Wu, X.H.; Sim, K.Y.; Tan, B.H.K.; Vittal, J.J.; Pereira, J.T.; Goh, S.H. Minor coumarins from Calophyllum teysmannii var. inophylloide and synthesis of cytotoxic calanone derivatives. Helv. Chim. Acta 1998, 81, 1404-1416. [CrossRef]

50. Cao, S.G.; Sim, K.Y.; Goh, S.H. Three new coumarins from Calophyllum teysmannii var. inophylloide (Guttiferae). Heterocycles 1997, 45, 2045-2052.

51. Kulkarni, M.V.; Kulkarni, G.M.; Lin, C.H.; Sun, C.M. Recent advances in coumarins and 1-azacoumarins as versatile biodynamic agents. Curr. Med. Chem. 2006, 13, 2795-2818. [CrossRef] [PubMed]

52. Palmer, C.J.; Josephs, J.L. Synthesis of the Calophyllum coumarins. Part 2. J. Chem. Soc. Perkin Trans 1 1995, 3135-3152. [CrossRef]

53. NAPROC-13 RMN Spectroscopic Database USAL. Available online: http://c13.usal.es (accessed on 17 February 2017).

54. Gaurav Taneja, A.G.; Raghuvanshi, A.; Kant, R.; Maulik, P.R. Diversity-oriented general protocol for the synthesis of privileged oxygen scaffolds: Pyrones, coumarins, benzocoumarins and naphthocoumarins. Org. Biomol. Chem. 2013, 11, 5239-5253.

55. Kamat, S.P.; D'Souza, A.M.; Paknikar, S.K.; Beauchamp, P.S. A convenient one-pot synthesis of 4-methyl-3-phenyl-, 3-aryl- and 3-aryl-4-phenylcoumarins. J. Chem. Res. Synop. 2002, 242-246. [CrossRef]

56. Sancho, R.; Medarde, M.; Sánchez-Palomino, S.; Madrigal, B.M.; Alcamí, J.; Muñoz, E.; San Feliciano, A. Anti-HIV activity of some synthetic lignanolides and intermediates. Bioorg. Med. Chem. Lett. 2004, 14, 4483-4486. [CrossRef] [PubMed]

Sample Availability: Samples of the compounds are available from José Luis López-Pérez, E-Mail: lopez@usal.es. 